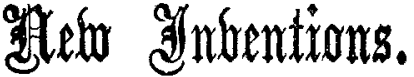

\section{IMPROVED HIP-SPLINT.}

APPRECIATING the difficulty of obtaining bony union in all fractures about the hip-joint (and this $I$ take to be due to want of proper apposition with consequent want of proper fixation of the bony fragments and neglecting by thus fixing both lower extremities the pelvis is fized. Extension is obtained by means of screw $\mathrm{F}$. The hip-joint is prevented from sinking into the bed by the back-splint $\mathrm{c}$, which is movable along the slot. To obtain absolute approximation of the fragments in capsular fractures pressure must be made on the great trochanter of the injured side, and this is provided for by the screw $\mathrm{E}$, which, when turned gradually, approximates the upper ends of the two long side-splints. The splint is reversible, so that it may be used for either

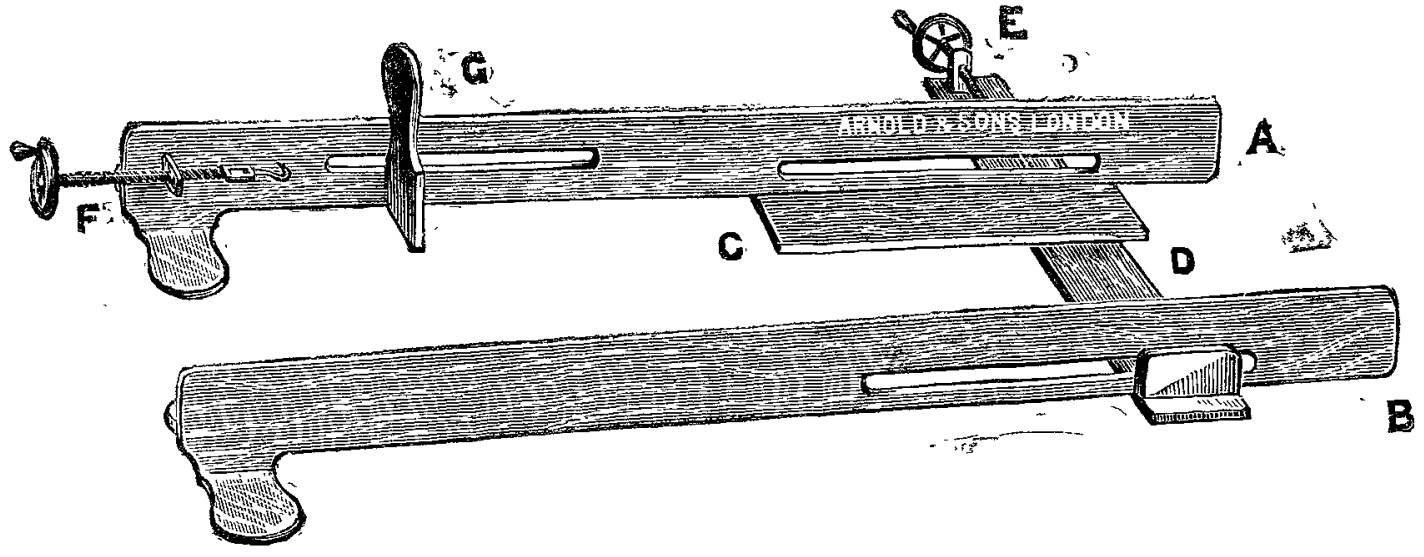

to fix the entire pelvis during treatment), the splint I/ side of the boay; also, as it is detachable, one sidehave had made for me by Messrs. Arnold and Sons of West splint can be used if required.

Smithfield meets all these requirements. It consists of two long side-splints $A$, with sliding foot-piece $G$, and
A. HERBERT BUTCHER, Surgeon to the Birkenhead Borough Hospital.

\section{THE “UNIVERSAL" TEAPOT。}

TEA properly made should be an infusion and not a decoction, but the vessel in which thls beverage is ordinarily prepared is more adapted for the latter process than the former. In our issue of Nov. 30th, 1895, we described a new tea infuser from which we obtained very satisfactory results, but the peculiarity of its construction rendered it practically useless unless a full pot of tea was required. The object to be aimed at in the construction of a really good teapot is, of course, the separation of the spent tea leaves from the hot infusion; and this Messrs. George Donald and Co., of Central-chambers, Glasgow, seek to accomplish by attaching to a chain, which passes through the lid of the pot, a small vessel for containing the

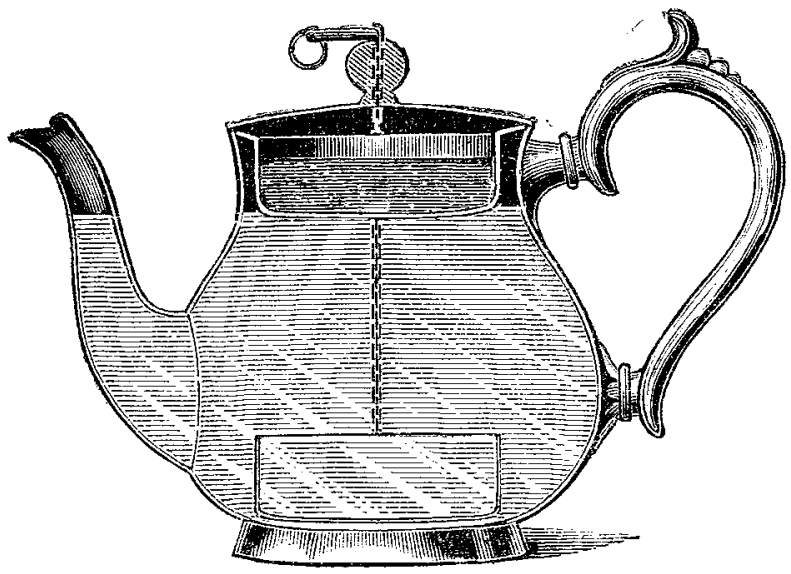

tea (see illustration). This vessel or infuser is allowed to rest at the bottom of the pot until the tea is "drawn" and is then elevated into the lid by means of the chain and kept in position by a pin passing through one of the links. The "Unirersal" teapot is made in brown ware, stone ware, and china, the best materials of which teapots can perhaps be made; and for the end in view-namely, the making of an infusion and not a decoction-the contrivance is almost all that can be wished. We would point out, however, that it is far from desirable to use a brass chain however heavily it may be plated with silver (in the present iflstance it is triple plated), as the contact of the two metals is likely to set up an electrical action. A chain made from pure aluminium would be far preferable.

\section{NUTRIENT SUPPOSITORIES}

THE nutrient suppositories for rectal feeding manufacttired by Messrs. Parke, Davis, and Co. are about an inch long and half an inch in diameter at the base. Each contains about 125 grains of fresh lean beef almost entirely peptonised: They are firm in consistence and have a smooth, dry surface.

\section{GELATIN CAPSUTESS.}

Messsis. Parke, Davis, and Co., of 21, North Audley: street, Grosvenor-square, have forwarded to us samples of their improved empty gelatin capsules, by the use of which the difficulties of administering unpalatable powders are reduced to a minimum. The capsules are made in ten sizes, differing greatly in their several dimensions, but all on the same principle. The larger sizes very much resemble short, round-ended, glass test-tubes, such as are used by chemists everywhere, but are without the ordinary everted border, and have a well-fitting cover, consisting of a similar but shorter tube sliding over the other. For administration by the mouth they are made in seven sizes, the smallest of which is about as large as an ordinary three-grain pill, and will contain either three-quarters of a grain of sulphate of quinine or one grain of powdered aloes or rhubarb. The largest of these is about a third of an inch in diameter and one inch long when closed; it will hold eight grains of silphate of quinine and about ten grains of powdered aloes or rhubarb. By means of them it is also easy to swallow nauseous uncoated pills without tasting them. The capsules are hard but elastic, they are smooth, the covers fit well, and the shape is convenient for being swallowed, but if held in the mouth they dissolve before long. There are also three sizes having a tapering end for rectal administration and three for veterinary and vaginal capsules. The latter are convenient for the local application of medicated cotton. A special filler is supplied for powders and pills. 